\title{
Using Cloud Infrastructure to Support Higher Education: A Case Study of Managing a Course Web Page with the Google Sites
}

\author{
http://dx.doi.org/10.3991/ijet.v8i1.2367 \\ E. Pjanić ${ }^{1}$, A. Hasanović ${ }^{1}$, N. Suljanović1 ${ }^{1}$ A. Mujčić ${ }^{1}$, D. A. H. Samuelsen ${ }^{2}$, O. H. Graven ${ }^{2}$, B. Thyberg ${ }^{2}$ \\ ${ }^{1}$ University of Tuzla, Tuzla, Bosnia and Herzegovina \\ ${ }^{2}$ Buskerud University College, Kongsberg, Norway
}

\begin{abstract}
In this paper we analyze the requirements for the complex information system used to support a modern global university. We outline the architecture for this system based on the emerging cloud computing platforms and present an example of managing a university course by incorporating different Google cloud services within the Google Sites.
\end{abstract}

Index Terms - cloud, course management, Google, web sites.

\section{INTRODUCTION}

We live in the fast-paced globalized world, which is largely technology driven. New demands are placed on every aspect of life, in particular the higher education. Under these circumstances, modern universities are expected to provide an improved education which is more focused on real-life practical skills, while at the same time increasing enrollments and operating under even tighter budgets. Furthermore, in order to offer their services to a wider range of population, universities are expected to change their mode of operation from a traditional one, tied to a single location, to a new model that is more appropriate for a geographically dispersed education. Complex computing and communication infrastructure is required to support this transition. Such ICT infrastructure is expensive taking into consideration the costs of software, equipment, maintenance, space/facilities and power consumption. These costs could be reduced by utilizing the cloud computing services offered on the Internet. Moreover, the savings would be substantial if the existing applications already offered in the cloud could be utilized for this purpose.

In this paper we analyze the requirements for the information system of a modern university and we investigate how the Google cloud infrastructure could be utilized to address these requirements.

\section{INFORMATION SYSTEM REQUIREMENTS}

In order to administer the study and research processes at a university, a complex information architecture is required. This architecture comprises various information systems that implement the support for ongoing business and educational processes at the university. Integration and information exchange among these subsystems is essential for providing the adequate accessibility and usability of the overall system $[1,2]$. This decentralized infrastructure should provide various services. In this section we review those that are of utmost importance for the envisioned university.

\section{A. Identity management}

This service is important because it provides user provisioning and access control to all subsystems. With this service a user logs in once and gains access to all components of the university information system without being prompted to log in again.

\section{B. Communication}

Communication is the most important aspect of a geographically dispersed university. This is due to the fact that the students and professors are not necessarily present at the same location throughout the semester. Therefore different communication channels should be provided to reduce the effects of this significant obstacle.

Multimedia communications such as voice and video are required for holding online lectures, office hours and faculty meetings.

Email, discussion forums and wiki-pages are essential tools of non-real time communication and must be available to all students, professors and administration staff.

\section{Content management and publishing}

Large amount of content is authored by everyday activities at a university. The information system should support content generation, be able to store large amounts of data originating from research, study and administrative activities and provide role based access to the stored content. Additionally, system should be capable of handling data in various formats such as audio, images, video, text, slides and simulations. Furthermore, the data retrieval component should include the search capabilities.

\section{Custom services development and deployment}

Universities are dynamic environments with constantly changing procedures and regulations. Therefore, the existing components of an information system should be modular and adjustable. Moreover, it should be possible to develop and deploy custom services that are tailored to the specific needs of the institution. These services must be able to communicate with the other components in the system. Hence, a common development and deployment platform which includes a set of standardized API for 
development of new applications is an important requirement.

The mainstream approach to address the former requirements is to establish an information infrastructure on the university premises. Universities often prefer to use open-source solutions to build the components of this system, because of their accessibility, flexibility and non existing software costs. There are many open-source solutions that can fully address individual aspects of the identified requirements, such as:

1. Moodle for the course management

2. The Big Blue Button for on-line lectures with video and audio support.

3. Zimbra or Zarafa for email services

4. Apache and Ngix for Web services

5. WordPress, Drupal, Joomla for content management services

6. Ruby on Rails, DJango, Play etc for custom services development.

However, there are important issues that have to be considered when using these components within a university information system, such as:

- Operational and setup costs related to the hardware, space/facility and power consumption could be substantial.

- Capable IT personnel are required for configuration and maintenance of this variety of open source solutions.

- Integration problems can arise, since these components have been built with different technologies, and are not necessarily designed to interoperate with each other [3].

- Scalability can be an issue especially for a large university.

- There is a lack of adequate off-the-shelf user provisioning component.

Recently offered cloud computing platforms have been designed to specifically address the majority of these issues. There are many Cloud providers on the Internet, such as Amazon, Microsoft, Rackspace, Heroku, etc. However, we found that the Google Cloud platform offers the most versatile set of services.

In the following section we describe how the Google cloud platform could be utilized as a complete solution for a university information system.

\section{GOOGLE CLOUD AS A UNIVERSITY INFORMATION INFRASTRUCTURE}

Higher education institutions can register their domains to be managed, without any cost, within the Google cloud infrastructure. By entering the Google Apps for Education program, a university gets the rebranded Google applications suite, already running in the Google cloud, which can be configured and utilized for their purposes. Moreover, custom applications can be developed using the Google App Engine and deployed to run within the Google cloud. For the registered domain, Google also provides an admin panel which can be used for users and groups provisioning.

University procedures usually require a complex fine grained provisioning system with multiple administrator roles, which is currently not supported by the Google. However, Google provides Google Apps Directory Sync (GADS), a utility that adds, modifies, and deletes users, organizational units, groups, shared contacts, and calendar resources in the Google domain, based on the data obtained from a LDAP directory server.

GADS can be installed on a local server on the university premises, and update the university Google Domain to match the university LDAP directory. This directory sync is performed in one direction, since it never updates or changes the university LDAP directory information.

Once provisioned through the admin panel or via the GADS LDAP sync, any user can log into their university Google cloud account and utilize the provided applications. The applications, already running in the cloud, can fulfill most of the requirements identified in the previous section. We propose the following use case for the existing Google services:

1. Google+ hangouts - for holding remote office hours and lectures with the support for video, audio and presentations (pdf, ppt, pptx, odp)

2. Gmail with Google Talk plugin - for email, chat, video and voice communications

3. Google Sites and Blogger - for building web pages

4. Google Docs and Google+ - for content management services and collaboration

5. Google Drive - for storage and content sharing

6. Google App Engine and Google Apps Scripts - for custom applications development and deployment

7. Google Forms - for course quizzes, grading and surveys

This is not the complete list of tools and services provided by Google. Furthermore, the listed tools are flexible enough to be utilized for other purposes not mentioned in the list.

\section{UNIVERSITY COURSE MANAGEMENT WITH THE GOOGLE SiTES}

In this section we describe how the tools listed in the previous section could be used to manage courses in higher education institutions. We focus on the Google Sites as the central part of the system for course management.

Google Sites provides a simple site creation system by which teachers alone can design, implement and manage websites for their courses. The Sites can be easily combined with other Google tools in order to incorporate documents, spreadsheets, calendars, forms, maps, video and a range of interactive gadgets into the course web pages. Google Sites management and creation system allows the creation of different types of web pages based on predefined templates, which additionally accelerates the course sites creation process. Templates can be selected from a range of public templates or from a set of templates that are published within the university domain. This means that teachers do not need to write any HTML code for their web site or to do any complicated adjustments. Hence, by using this infrastructure the site maintenance costs could be significantly reduced, since there is no need for dedicated servers or a large IT department. 
Although there are a number of options to choose for site access permissions, the two models of authorization are most commonly used for university courses. The first, which allows anyone without any authentication to access the course web page, and the second, which allows access only for the authenticated users that have Google accounts that belong to the university domain. The first model is good for a site with general information and presentation of the institution or a personal web page, such as web pages of the university personnel, and the later one is tailored for the sites that require authorization and authentication in order to allow access for a limited audience such as a course web site with materials that need to be accessible only for the students at the university. Here, we assume that the university is the member of the Google Apps for Education program and has its domain configured to be managed by the Google cloud infrastructure.

\section{A. The Domain Administration}

The university domain is administered through the control panel which provides a convenient way of activating services and adjusting other settings within the domain. Administration privileges are role based. There can be arbitrary number of roles with a different set of privileges.

The administrator of the domain can create suborganizations within the university that have a different set of activated Google services. The user account can be assigned to a particular sub-organization. Suborganizations within the university can be organized in different ways i.e.: by the departments, by the students' years etc. Furthermore, the domain accounts can be assigned to the Google Groups, which are a convenient way of communication and collaboration among the users. Instead of entering individual addresses, the users can send messages and/or share their documents and other resources within the groups.

The user accounts can be created through the LDAP synchronization, as discussed in Section III, individually through the control panel, as shown in Figure 1, or can be bulk uploaded in the form of a comma separated file (CSV), which is especially useful if creating a large number of users. Created accounts get custom email address, shared calendar system, tools for document processing and sharing, tools for creating sites, video and voice communication and many other Google services.

\section{B. The Example Course Site}

If the Google sites service is activated by the administrator, every user of the university domain can create a site using the Google Sites. The address of the web site is in the form http://google.com/a/yourorganization.com/your-site, where your-domain.com is the domain name of the university. Additionally, the sites can be assigned a custom URL mapping such as http://yoursite.your-organization.com. Custom URL mappings can only be configured by the domain administrators and are convenient for certain types of sites that are of the broader interest for the university, for example the sites for the courses.

The example course site we describe in this section, called iJET Example Course, can be accessed at the following address http://ijet-example.ictlab.com.ba. In order to present the powerful features of the Google Apps that are interesting for higher education, the site is organized into the six simple but yet easily managed web pages as shown in Figure 2.

A site access permissions can be set from the public permission, meaning anyone on the Internet can view the site, to the fine grained page level permissions where only a certain user could edit or read the page. For the example web page, the demo student account name is: ijet-student with the password: ijet-student.

Our example site access permissions are set in the way that only the teachers assigned to teach the course can

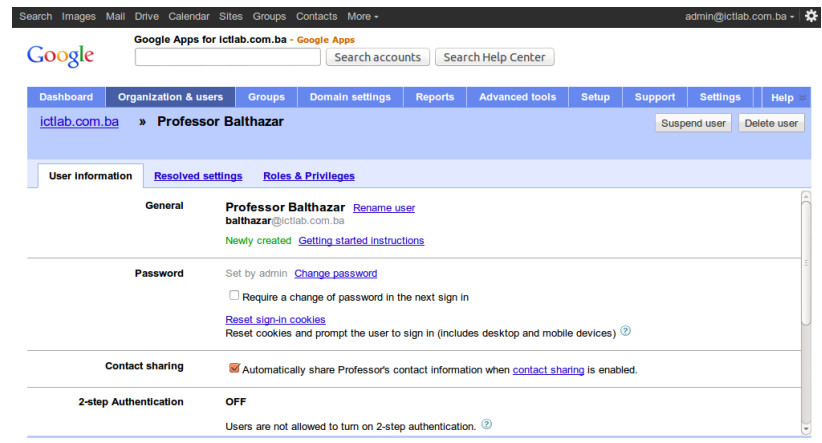

Figure 1. The Google Apps user management control panel

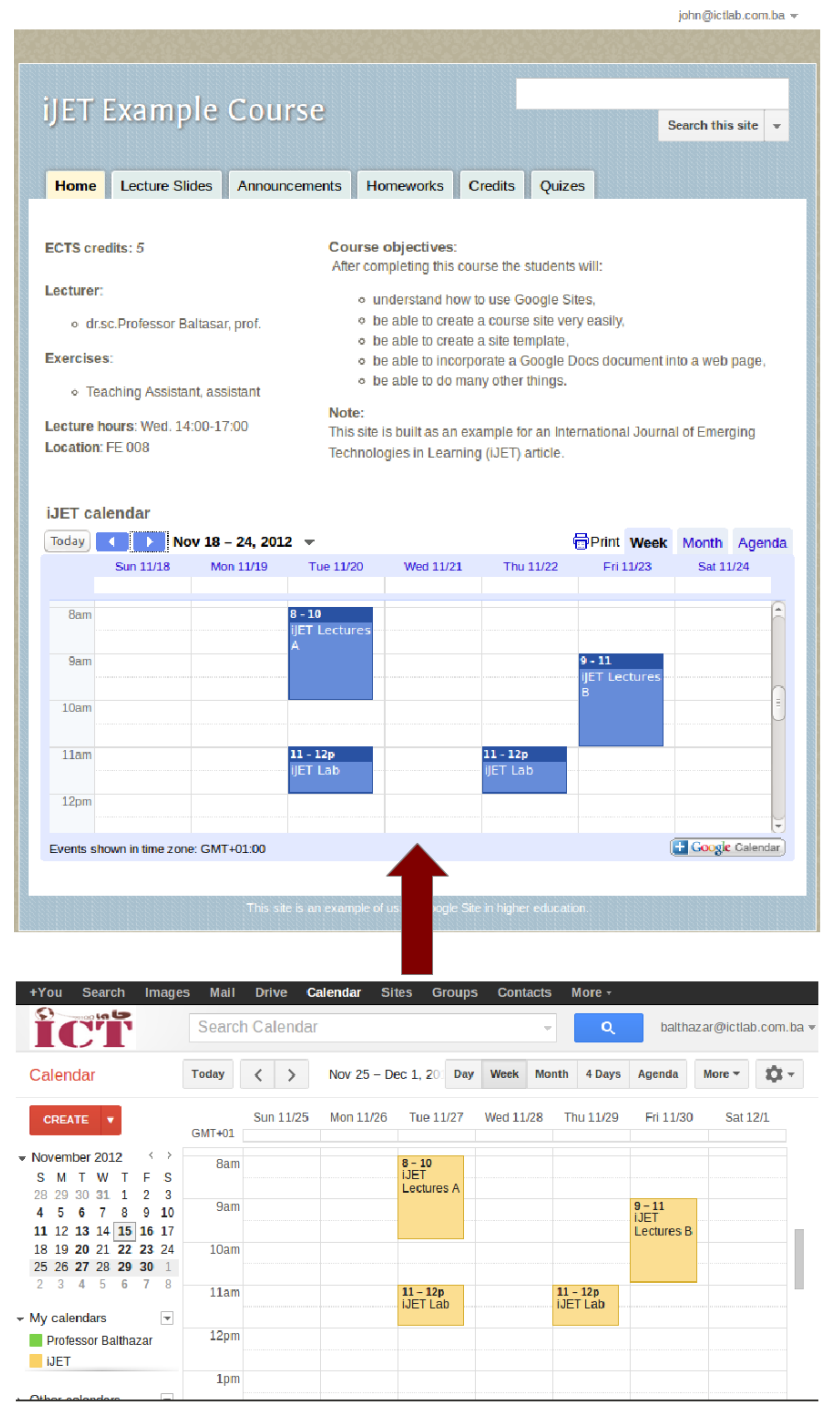

Figure 2. Homepage with the calendar integration 
manage the site, upload files and leave comments. The students can view all the pages, download attachments and read the comments. Public access is set only for the Announcements page in order to enable RSS feed of the announcements posts. When accessing the site, the Google Apps system authenticates the user and shows a user interface according to their credentials. It means that the teachers and students will not be presented with the same user interface since the teachers can edit, while the students can only view the site.

One of the interesting features is the calendar service which is integrated on the Homepage. The course calendar contains all lectures, labs and exam schedules. It is managed by the teachers using their personal Google Calendar, as depicted in Figure 2. The course calendar is shared among the teachers and is set to be viewable by the students within the domain. Students who can view the Homepage can easily browse calendar records and copy them to their calendars with a single click. Furthermore, it is possible to combine several Google calendars into a single calendar and place it on a web page using the Google Calendar widget.

Lecture Slides page is created as the file cabinet type of a page. This type of a page contains a list of files with the lecture slides and other materials organized in folders, as shown in Figure 3. The students can download and/or view the files directly in the browser, while the course teachers can upload the files and add comments. Hence, the user interface for the teachers is slightly different than the interface for the students.

The Google Sites web page can be set to notify students about important updates so that they don't need to access the site frequently. This feature is provided by the announcements type of page and notifications are implemented via the RSS feed. On the Announcements page of our example course site the students can subscribe to the RSS feed by clicking on the appropriate link.

The Google Docs documents can also be integrated into the web page. The Credits page, shown in Figure 4, contains a Google Docs spreadsheet with the credits which the students have earned throughout the semester. The teachers have the spreadsheet shared from their Google Drive. All changes that are made in the spreadsheet through the Google Docs are automatically published to the course web page. This means that once the Google Docs document is incorporated into the web page the teachers need only to work with the original document without any intervention on the web page. Similarly, any type of the Google Docs document can be incorporated in a web page, such as text documents, drawings, presentations and other.

One important feature required for the course management is a possibility of making surveys and quizzes. This feature can be implemented through the web forms using the Google Forms widgets, as shown for the example web site in Figure 5. There are different types of widgets that can be placed in the form, such as the plain text widget, multiple choice widget, list widget etc. Moreover, the form has an option of branching depending on the given answers. Also, there are a large number of themes that can be applied to the form in order to improve its visual presentation. Once the form is created, the form can be incorporated into the web page or sent within an email. The form is bound to the Google Docs spreadsheet and every submission of the form data is inserted into the spreadsheet as a separate row. The spreadsheet data can be analyzed later using all the features of the Google Docs spreadsheet, such as statistics calculations, graphs etc. In case the form is used for the quizzes, the user ID can be incorporated within the submitted data, which can then be linked with the student's earned credits spreadsheet and used for automatic grading purposes.

\section{CONCLUSION}

Google cloud infrastructure can be utilized to host information services required to operate a modern geographically dispersed university. The default Google cloud services are powerful enough to be utilized for the management of university courses. If custom features are required for a particular web site, they can be developed and implemented using either Google App Scripts or the more powerful Google App Engine.

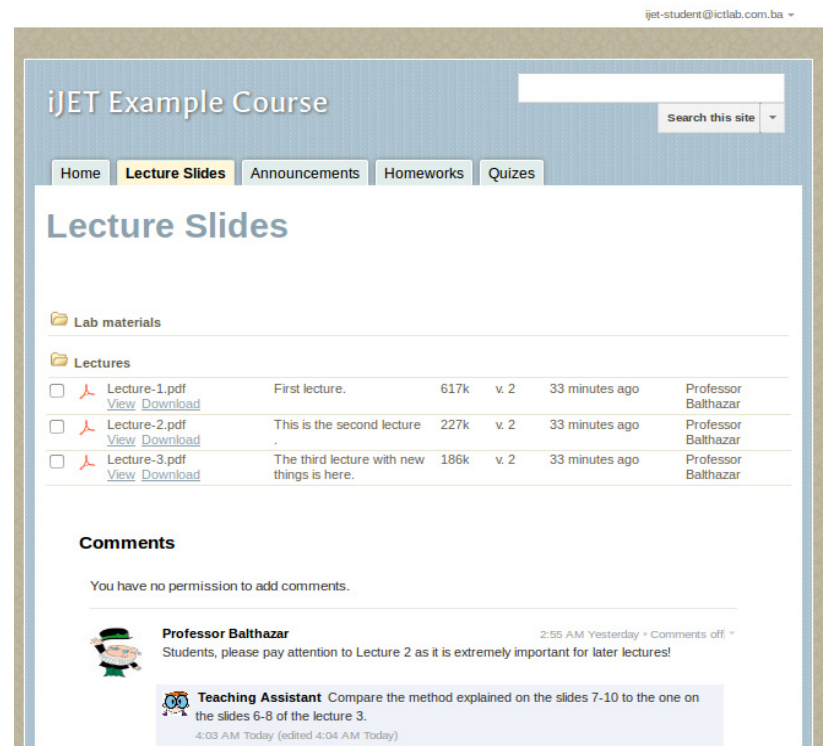

Figure 3. Lecture slides file cabinet page

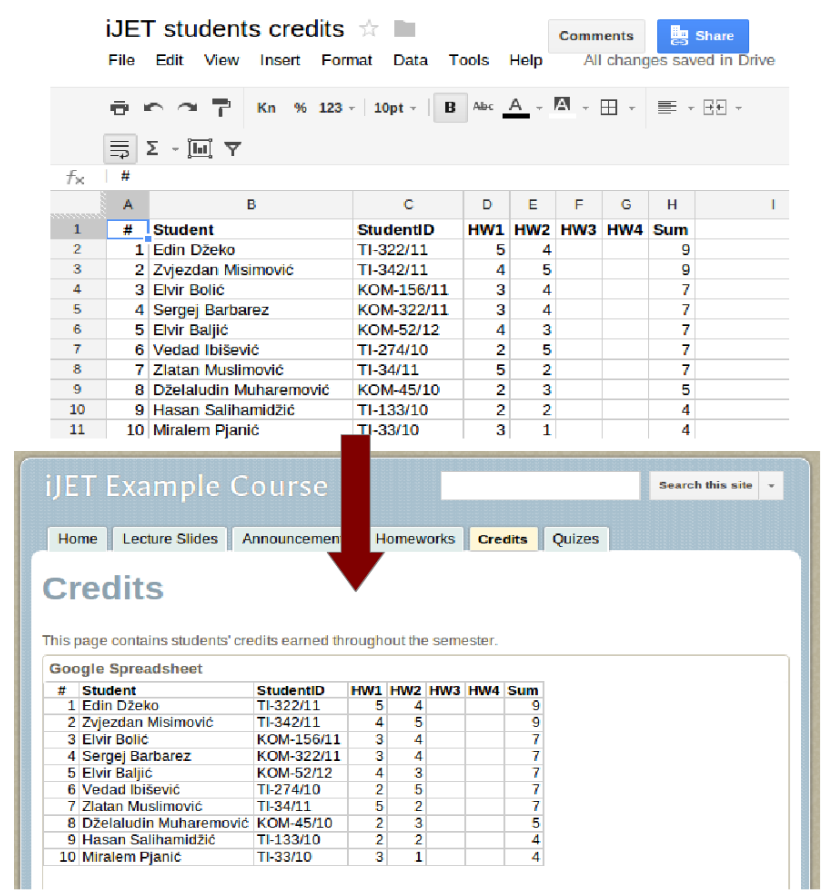

Figure 4. Spreadsheet integration in the Credits page 


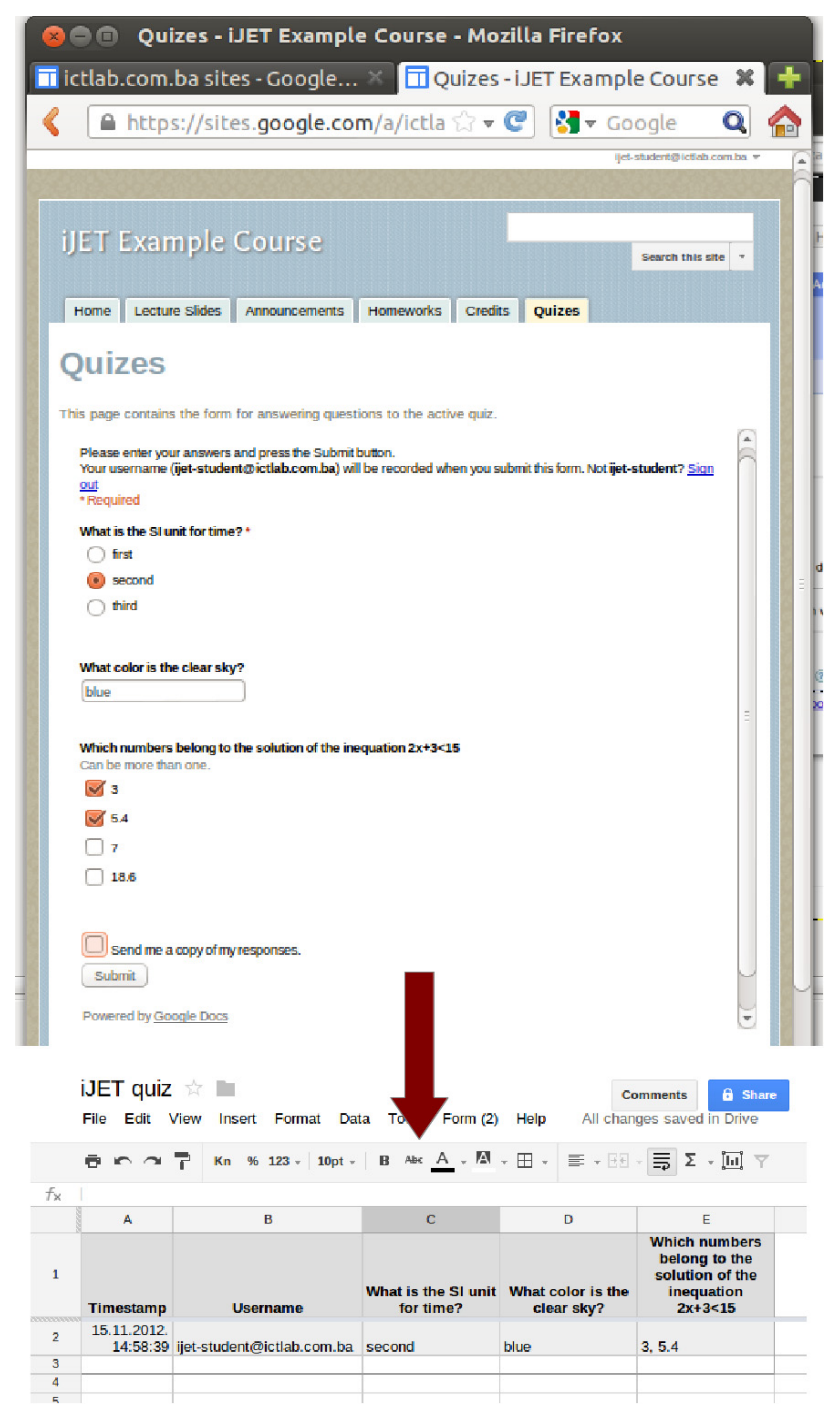

Figure 5. Course quiz using the Form widget

\section{REFERENCES}

[1] T. Kudrass, "Integrate University Information Systems," Proceedings of the 8th InternationMagnetization as a function of applied field. Note how the caption is centered in the columnal
Conference on Enterprise Information Systems (ICEIS), Paphos, Cyprus, May 2006.

[2] Bischof, C., Gebhardt, M., Steves, "The Integrated CAMPUS Information System: Bridging the Gap between Administrative and E-Learning Processes," 11th EUNIS Conference, Manchester, UK, 2005.

[3] S. Graf, "An evaluation of open source e-learning platforms stressing adaptation issues," Fifth IEEE International Conference on Advanced Learning Technologies (ICALT), Kaohsiung, Taiwan, 2005. http://dx.doi.org/10.1109/ICALT.2005.54

\section{AUTHORS}

E. Pjanić is with the Faculty of Electrical Engineering, University of Tuzla, Franjevačka 2, 75000 TUZLA, Bosnia and Herzegovina (e-mail: edin.pjanic@untz.ba).

A. Hasanović is with the Faculty of Electrical Engineering, University of Tuzla, Franjevačka 2, 75000 TUZLA, Bosnia and Herzegovina (e-mail: amer.hasanovic@untz.ba).

N. Suljanović is with the Faculty of Electrical Engineering, University of Tuzla, Franjevačka 2, 75000 TUZLA, Bosnia and Herzegovina (e-mail: nermin.suljanovic@untz.ba).

A. Mujčić is with the Faculty of ElectrIcal Engineering, University of Tuzla, Franjevačka 2,75000 TUZLA, Bosnia and Herzegovina (e-mail: aljo.mujcic@untz.ba).

D. A. H. Samuelsen, is with faculty for technology, Buskerud University College, Kongsberg, Norway (email: dag.samuelsen@hibu.no).

O. H. Graven, is with faculty for technology, Buskerud University College, Kongsberg, Norway (e-mail: olaf.hallan.graven@hibu.no).

B. Thyberg, was with faculty for technology, Buskerud University College, Kongsberg, Norway (e-mail: brit.thyberg@hibu.no).

This study is part of the "Norbotech project "Norwegian Bosnian Technology Interaction based on sustainable Systems Engineering and Embedded Systems in the field of Cloud Computing and Signal Processing. The Norbotech project is supported by the Norwegian Ministry of Foreign Affairs Programme in Higher Education, Research and Development (HERD) in the Western Balkans 2010 - 2014 within the field of ICT. This article is an extended and modified version of a paper presented at the International Conference on Interactive Collaborative Learning (ICL2012), held 26 - 28 September 2012, in Villach, Austria. Received 15 November 2012. Published as resubmitted by the authors 27 February 2013 . 